\title{
O cangaço e o (ser)tão nacional: Deus e o diabo na terra do sol e a literatura de cordel
}

\author{
Banditry and the national wilderness: God and the \\ devil in the land of the sun and the cordel literature
}

\author{
Paulo Estevão Mortati Fuzinelli** \\ Raimunda de Brito Batista**
}

\begin{abstract}
Resumo: A Literatura de Cordel reflete em grande parte a cultura da região em que está inserida, ou seja, o Nordeste brasileiro. Assim também o filme de Glauber Rocha, Deus e o Diabo na Terra do $\mathrm{Sol}$, refere-se a essa cultura. Neste trabalho, levantaram-se hipóteses para comparações, evidenciando a diferença e também a constatação de algumas semelhanças entre determinados folhetos que foram escritos baseados no cangaço e no sertão brasileiro e as imagens produzidas por Glauber Rocha em seu filme, no qual os mesmos assuntos são tratados. Os folhetos que foram utilizados para análise estão presentes no acervo de Literatura de Cordel, localizado na Biblioteca Central da Universidade Estadual de Londrina.

Palavras-chave: Literatura de Cordel. Cinema Novo. Cangaço. Sertão.

Abstract: The Cordel literature reflects the culture of the region it belongs to, that is the northeast of Brazil. In the same way the film by Glauber Rocha, Deus e o Diabo na Terra do Sol, also refers to the same culture. This work considered a number of hypothesis in order to compare the differences and the similarities among brochures which were written based on social banditry - known as cangaço - and the Brazilian backlands, and the images produced by Glauber Rocha in his film, where the same subjects are discussed. The brochures used for the analysis are in the Central Library of the State University of Londrina.

Keywords: Cordel Literature. New Cinema. Social banditry. Wilderness.
\end{abstract}

\section{Introdução}

A Literatura de Cordel, que tem em sua representação no poeta popular e no repentista, surgiu na Península Ibérica e aqui no Brasil instalou-se no Nordeste. Vendida em feiras, praças, mercados, entre outros lugares,

Graduando. Universidade Estadual de Londrina - UEL - paulofuzinelli@gmail.com

Profa Dra. Universidade Estadual de Londrina - UEL - raimundajoao@ gmail.com 
é capaz de divertir, informar e caracterizar os costumes da região em que foi produzida. É feita em versos, com estrofes na maioria das vezes do tipo sextilhas, septilhas ou décimas. O poeta popular serve-se das mais variadas temáticas, acrescentando ou não suas fantasias, fazendo uso de acontecimentos da atualidade ou então de temas próprios da região, como o cangaço e a religiosidade, que são divididos em ciclos. É no chamado "ciclo heróico" que estão exaltadas as proezas dos cangaceiros. A grande criatividade existente no cordel demonstra-se também através das capas, realizadas, na maioria dos casos, pelo processo das xilogravuras, que são ilustrações feitas a partir de um molde impresso em uma matriz e madeira.

O filme Deus e o Diabo na Terra do Sol, que se insere no movimento do Cinema Novo, o qual de certa forma adotava o dístico "Uma câmera na mão e uma ideia na cabeça", propõe-se, dentre suas características, uma não alienação cultural, além da retratação da realidade do Brasil, com a adequação da linguagem à situação da época e também ao subdesenvolvimento do país.

Resumindo o enredo, tem-se um filme que conta a história do cangaceiro Manuel e de sua mulher Rosa, que são obrigados a viajar pelo sertão pelo fato de Manuel ter assassinado seu patrão após ser humilhado, e eles vão encontrando outras personagens durante sua caminhada. O filme mostra claramente elementos do cangaço, do sertão e do homem que o habita.

A proposta do presente trabalho é realizar comparações entre o filme de Glauber Rocha e folhetos de cordel existentes no acervo da Biblioteca Central da Universidade Estadual de Londrina, nos quais são abordados os mesmos assuntos.

\section{Literatura de Cordel: representação, origem e ideologia}

Sobre o surgimento deste tipo de manifestação literária popular, há várias hipóteses. Sabe-se que já existia em Portugal e Espanha antes do século XIX e, inicialmente, foi conhecida como "folha solta" ou "volante".

A Literatura de Cordel desembarcou no Brasil por volta dos séculos XVI e XVII, juntamente com os colonizadores lusos, em Salvador, na Bahia. O início do cordel impresso no Brasil, segundo Galvão (apud RESENDE, 2006, p. 412), deu-se em 1893, com Leandro Gomes de Barros, e seu apogeu 
ocorreu nas décadas de 1930 e 1940. De lá para cá assume ares nordestinos com características bastante peculiares dessa região, onde os poetas populares retratam a vida do sertanejo, como costumes, crendices, realidade e cultura, com uma linguagem excepcionalmente singular. Constitui-se basicamente de narrativas escritas em versos, com estrofes do tipo sextilhas, septilhas ou décimas, e impressas em papel jornal. Com número variado de páginas, sempre números pares, possui em sua capa uma xilogravura, que é uma gravação em madeira estampada a tinta no papel. São expostos em cordas nas feiras, onde também são cantados. Apesar de o cordel não ser genuinamente nordestino, sofreu uma enorme adaptação e atualmente é tido como tal.

Essa literatura deve ser, em seu caráter íntimo, relacionada ao meio em que é constituída e por quem é produzida. Os seus principais representantes são poetas populares, em geral analfabetos ou semi-alfabetizados, muitas vezes com mentalidade arcaica e conservadora. Por existir certo preconceito, isto é, por ter sido considerada literatura menor, ela foi afastada do meio intelectual. Proença $(1977$, p. 57) reforça esta constatação: "o cordel tem caráter errante, o autor se subordina ao esquema que lhe é imposto, os preconceitos 'afastam' o cordel da elite intelectual, faculdades de letras inclusive", e também ressalta:

O cordel, mesmo quando apologista do lugar comum, ainda aí é uma forma original de ruptura com uma literatura oficial e regular, a que o povo não tem acesso. Claro que esse cordel ao mostrar-se produto de "marginalização" literária, e entendido enquanto literatura não "regulamentar"; também não escapa às redes sufocantes do sistema, influenciado por uma imprensa (jornais e TV) normalmente dirigida, quadrinhos, cinema americano, órgãos oficiais de comunicação, hoje empenhados implicitamente na consolidação de uma aldeia global. (PROENÇA, 1977, p. 57 - 58).

Existem também os poetas que se estabelecem nos grandes centros, migrando para regiões como São Paulo e Rio de Janeiro, onde ainda costumam produzir os temas antigos, mas criam histórias para adaptá-las à nova condição de vida na qual estão inseridos.

A temática da Literatura de Cordel é imensamente diversificada, propriamente todo e qualquer assunto serve para se construir um folheto, desde romances tradicionais como os Carlos Magno e os Doze Pares de França, até acontecimentos da atualidade, do cotidiano, como desastres, mortes, cangaço, ideologias, religiosidade etc. Muitos desses acontecimentos fazem parte do dia a dia do cordelista. 
Paulo Estevão M ortati Fuzinelli; Raimunda de Brito Batista

\section{Cinema Novo e Glauber Rocha}

Nasce no dia 14 de março de 1939, em Vitória da Conquista, Bahia, Glauber de Andrade Rocha, que mais tarde viria a ser conhecido apenas por Glauber Rocha. Filho de Adamastor Bráulio Silva Rocha e Lúcia Mendes de Andrade Rocha, foi criado dentro das normas do protestantismo e alfabetizado pela mãe. Mudou-se com a família para Salvador onde, na escola, começou a escrever e atuar em uma peça. Participou de grupos amadores e foi comentarista de programas de rádio. Começou a filmar no ano de 1959, mesma época em que entra para a Faculdade de Direito, que abandonou logo no começo para se iniciar - mesmo que brevemente - na área jornalística, onde sempre deixou clara sua paixão pelo cinema.

Motivados por diversos precedentes na cultura nacional, como o fim das companhias cinematográficas paulistas e o sentimento de dar voz ao povo, afastando a alienação presente nas telas brasileiras, alguns jovens cineastas se uniram para colocar sob suas lentes filmes mais substanciais, realistas e baratos. Baseados na Nouvelle Vague francesa e no realismo italiano criam o então Cinema Novo.

Na década de 50 inicia um embate entre estética e ideologia, colocando em pauta a necessidade de se refletir sobre a condição humana e se modificar a técnica cinematográfica, tornando seu preço acessível e capaz de comportar jovens com boas ideias. A partir do filme Rio, 40 graus (1955), Nelson Pereira dos Santos, seu diretor, é indicado como o empreendedor desse novo movimento, que se caracterizava pelo estudo, pela exploração, pela interpretação e pela recriação da realidade social do Brasil.

Em meados de 1960, Glauber Rocha trabalhava como crítico de cinema e repórter policial e tinha como projeto criar um movimento coletivo em favor da manifestação estética e cultural. Para Glauber, o mais importante era conseguir vencer as barreiras territoriais do Nordeste e que sua obra fosse verossímil tanto para o Brasil quanto para o resto do mundo.

O cinema era o grande veículo epistemológico para se conhecer o homem brasileiro. Além disso, criou uma forma autêntica de retratar essas histórias e guiar sua principal personagem para a revolução. Em 1962, patrocinado pelo Centro Popular de Cultura (CPC) da União Nacional dos Estudantes (UNE), é lançando Cinco vezes favela, filme dividido em capítulos, que retrata 
o cotidiano da população marginal carioca. Os capítulos foram dirigidos pelos principais pensadores do Cinema Novo.

Estes cineastas estavam no meio do resgate das ideias modernistas, que vinham de diferentes fontes, como a Tropicália e os teatros de esquerda. Em 1967, Glauber Rocha lança Terra em Transe, que encontra um paralelismo com a encenação de $O$ Rei da Vela, de Oswald de Andrade, realizado pelo Teatro Oficina. A partir deste momento, a discussão social ganha mais força que o existencial e a busca de identidade da população torna-se o viés necessário para se filmar histórias. A arte popular é um processo eminente da revolução popular: nesse processo o artista tende a realizar a legalidade histórica que lhe falta. A proposta do CPC de arte popular revolucionária é então rejeitada por Glauber, acusando a mesma CPC de populista.

O popular usado na estética do Cinema Novo recusa a identidade folclorista. Sua importância está na dimensão metafórica e o popular não é visto como parte integrante da vida social, mas é o avesso do habitual, por onde permeiam as figuras míticas e lendárias dessa população. Neste contexto, o popular vira um registro não só nacional como também terceiro-mundista.

O Cinema Novo se transforma na revolução pela qual se busca a novidade da imagem, destituindo toda a casualidade presente nas imagens do cinema nacional. A proposta estética do Cinema Novo gravitava em torno da dicotomia entre ruptura e convergência da ambientação e a tradição histórica cultural do Brasil.

Glauber é responsável por estampar a face brasileira nas telas do cinema e foi o propulsor de um movimento de jovens inquietos que ganhou repercussão internacional, além de ser um grande expoente do cinema nacional e, sem dúvida, o mais polêmico e influente.

Glauber foi sempre atraído por estruturas bipolares, recorrendo a imagens barrocas para denunciar as desigualdades sociais que estão na base do modelo econômico e político vigente no País. Nos anos 1960, em plena ditadura do regime militar, Glauber e seus colegas de geração faziam filmes para mudar o mundo. Para fazer filmes politicamente revolucionários, eles achavam que a linguagem também precisava ser revolucionária. Era esse o projeto de Glauber (e do cinema novo). Produziu duas obras-primas, Deus e o Diabo na Terra do Sol e Terra em Transe. (MERTEN, 2003, p. 177). 
Paulo Estevão M ortati Fuzinelli; Raimunda de Brito Batista

\section{Análise de Deus e o Diabo na Terra do Sol}

O filme se inicia com uma tomada panorâmica do sertão: um sertão sem vida onde a terra vale por si mesma, um sertão solitário. Logo no início do filme podemos notar este mesmo sertão como um local baseado na fé: fé não só em Deus e no milagre que podem receber, mas na esperança da melhora, da mudança de vida. Há certo tipo de crença em um destino, em que os fatos ocorridos são exatamente o que havia de acontecer, um destino que, na verdade, ninguém sabe se existe realmente.

Inicialmente, temos a figura de Manoel, um homem pobre que não compartilha de uma simples pobreza, mas sim de uma pobreza antiquada, uma vez que este não possui uma voz ativa na sociedade. É um homem que se submete ao que lhe é imposto, o que notamos ainda ao início do filme, já que o Coronel não quer pagar o preço pelo gado que morreu e insiste em dizer que o gado era de Manoel. Manoel vê-se obrigado a aceitar tal acontecimento, mas se vinga esfaqueando o Coronel. Nota-se também a presença do coronelismo, que é símbolo de autoritarismo e impunidade, característica marcante durante o filme todo.

Após a morte do Coronel, seus capangas vão atrás de Manoel e de sua família e acabam por matar a figura idosa de sua estirpe. A partir desse ponto, percebe-se a religiosidade presente na vida dessa família, pois seus integrantes precisam fugir, mas não o fazem enquanto não enterram essa senhora sob um signo cristão: a cruz.

Manoel decide seguir a figura de Sebastião, que é um homem de caráter messiânico e que proporciona visões idílicas. Após o trágico fim colocado em sua vida social, Manoel encontra como saída apenas sua junção a esse movimento religioso. A primeira aparição de Sebastião apresenta um grupo pequeno e pobre de pessoas, mas durante a segunda aparição nota-se que este grupo já se expandiu e faz uso de um estandarte. Percebe-se que a legitimação desse movimento se dá pelo dinheiro para atrair um número maior de fiéis, pois o movimento precisa se demonstrar mais harmonioso. Essa harmonia deriva desse estandarte e da construção de uma capela no alto do morro santo.

Esse movimento pode ser considerado marginal, contrariando dois grandes poderes da sociedade: a Igreja e o Estado. No entanto, essa marginalidade também persegue quem não age conforme sua conduta. Durante o assalto 
ao prostíbulo, os fiéis de Sebastião espancam as prostitutas e seus clientes e ainda roubam seus pertences.

Manoel se encontra neste movimento a fim de buscar uma verdade. Sua posição enquanto vaqueiro não lhe permite uma vida digna socialmente e sua sede pela mudança da realidade na qual está inserido o leva a seguir Sebastião. Sebastião e Manoel são apenas mais um retrato de um povo humilde e sem instrução que busca a melhoria da condição de vida através de visões religiosas extremas, como a de Antônio Conselheiro: "O sertão vai virar mar e o mar vai virar sertão.", frase que é repetida durante o filme todo.

A figura da mulher, representada por Rosa, é uma alegoria para a consciência, para o "ceticismo". Rosa apenas vê a salvação de sua vida através do trabalho, da própria realidade que a cerca. Ela reluta em continuar onde vive e insiste na tentativa de esclarecer o marido sobre a real finalidade do movimento. Rosa não acredita que houve modificação em sua vida, pois a miséria em que vive é a mesma e se permanecer naquele local, o fim é certo.

A partir dessas tentativas de Rosa, Manoel interroga Sebastião acerca da legitimidade do movimento, já que a pobreza o cerca e os "rios de leite" continuam imateriais. As respostas de Sebastião são dogmáticas e para Manoel são apenas respostas de seu líder religioso. Para os espectadores do filme, tal fato vai mais além, pois até então não havia como comprovar a não santidade de Sebastião. Para não criar maiores dúvidas a respeito da condição de pobreza e também da veracidade de sua santidade, Sebastião pede para Manoel sacrificar Rosa e um inocente, no caso, uma criança.

É apresentada ao espectador uma nova personagem: Antônio das Mortes, jagunço conhecido por matar cangaceiros. Antônio das Mortes vai para a igreja fechar um acordo com o padre e um latifundiário local para exterminar o movimento religioso comandado por Sebastião. O padre reclama não a falta de fiéis, mas a falta de dinheiro, evidenciando que a igreja não se preocupava com a crença dos fiéis, apenas visava a lucros, e o latifundiário reclama que o movimento prejudica as fazendas e que a capital não se preocupa em resolver o problema.

Até o momento, Sebastião não constituía uma ameaça, mas a partir disso, ele passa a se tornar um incômodo social. O latifundiário diz que naquela região existem apenas duas leis: a Lei do Governo e a Lei da Bala. Coronelismo real reforçado por outra fala do latifundiário: "Eu nunca resolvi 
uma eleição com votos."

Antônio das Mortes mata todos os fiéis, mas não alcança seu principal objetivo, que seria exterminar Sebastião, que foi morto por Rosa, que o mata para que ela mesma não seja morta. Manoel, que segura o corpo de uma criança, tem um momento de esclarecimento ao relatar que não pode vingar a morte de Cristo com o sangue de um inocente. Antônio das Mortes consente que Manoel e Rosa fujam para que narrem aos outros o que havia acontecido. Na saída, deparam com o cego Júlio, que os leva ao encontro de Corisco.

Ao encontrar Corisco, nota-se que o discurso que ele profere é o mesmo que Sebastião possui: o pobre não pode morrer de fome, a república e o governo são o mal da população e a população não pode morrer nas mãos desse governo, e também possui as armas de São Jorge para defendê-los. Mais uma vez o discurso religioso é usado para validar a justiça e esse discurso deixa o cangaceiro no mesmo grau de credibilidade do movimento de Sebastião.

Corisco é o último representante do movimento dos cangaceiros. Segundo o que ele relata, Lampião e Maria Bonita haviam sido mortos há três dias. Com isso, há a percepção de que o movimento do cangaço já se encontrava um tanto quanto enfraquecido por não possuir em seu grupo seus principais representantes.

Manoel surge em ambos os movimentos que são apresentados no filme como a força e a vitalidade de que eles necessitam: o movimento de Sebastião, para fazê-lo crescer, e o de Corisco, para reerguê-lo. Manoel pode ser representado como a população carente de líderes, que serve de massa de manobra para qualquer tipo de manifestação, independentemente da ideologia. Ele poderia flanar entre o movimento religioso e o movimento armado com todo desprendimento.

Ao entrar para o cangaço, Manoel é batizado por Corisco e recebe o nome de Satanás, o que se contrapõe a toda a ideologia místico-religiosa que até então cultivava. Enquanto o movimento de Sebastião tenta se legitimar através da religião, o cangaço se legitima através do terror.

Os homens matam para fazer valer a ideia de justiça que tanto almejam, enquanto as mulheres não compartilham desta visão, tentando alertar os maridos para abandonarem a vida marginal. Manoel diz: "Só se pode fazer justiça no derrame de sangue". Desta forma, ele diferencia a morte de culpados e inocentes, já que não se sente culpado por ter matado o coronel, mas se sente 
acusado por ter matado o noivo após um assalto em uma festa de casamento. A culpa que ele carrega o faz desistir de ser um cangaceiro.

Antônio das Mortes não compartilha do pensamento da elite dominante, mas o sofrimento da população lhe é torturante e aceita o pagamento do padre para ajudá-los a sair daquela situação. A partir desse discurso, percebe-se a proximidade que Antônio das Mortes tem com Deus, determinando o momento certo para acabar com o sofrimento das pessoas.

A cena final do filme é um plano aéreo do mar, em que Manoel aparece correndo em busca de sua liberdade, contrapondo-se com o início do filme, que é um plano aéreo do sertão. Tais planos traduzem-se em um jogo de interpretações relacionadas à célebre frase do filme: "O sertão vai virar mar e o mar vai virar sertão.".

Para concluir, o homem na terra de Deus e do Diabo só tem validade quando pega as armas para mudar o destino dos demais, sendo obrigado a conquistar a justiça através da força. Portanto, três elementos são indissociáveis: o ser, o lugar onde ele se insere e sua cultura.

\section{Análise dos folhetos}

A análise será feita em relação a alguns folhetos, que estão presentes no acervo de Literatura de Cordel na Biblioteca Central da Universidade Estadual de Londrina, e retratam o homem do sertão, o sertão e o cangaço. Nos exemplos transcritos, foi preservada a grafia original dos autores.

O folheto A morte comanda o cangaço, de Joaquim Batista de Senna, já começa retratando a cultura presente no cangaço e no sertão. A morte que não se vale de lei nenhuma, apenas ela própria colocando-se como aquela que guia o movimento do cangaço.

Na segunda estrofe, nota-se que o desespero do homem do Nordeste ocorre por causa dos cangaceiros que lá existem e pela seca. Esses dois elementos são equiparados, colocados lado a lado como coisas ruins e também vistas como castigo. 
Paulo Estevão M ortati Fuzinelli; Raimunda de Brito Batista

\author{
Há muitos anos passados \\ o nordeste brasileiro \\ vivia sempre assolado \\ todo povo em desespero \\ tristemente castigado \\ por sêca e por Cangaceiro (SENA, 1977, p. 1).
}

Os cangaceiros, para o autor do folheto, são bandidos, marginais que matam apenas por matar. Não possuem aquela ideologia disseminada popularmente de tirar dos ricos para dar aos pobres, apenas têm em si essa necessidade da bandidagem. "Roubavam e assassinavam / sem compaixão, sem clemência". (SENA, 1977, p. 1). Lampião, para uma parcela da população nordestina, é tido como uma espécie de salvador, um homem que possuía em suas práticas boas ações, mas para o autor ele é tido como um bandido, uma vez que assim se refere: "Aqui eu alego um caso / do bandido Lampião" (SENA, 1977, p. 3).

Fica bem evidenciado que o governo não possui voz ativa perante a ação do cangaceirismo, uma vez que não toma atitudes para combatê-lo. Essa afirmação pode ser comprovada em algumas partes do folheto, como: "Pois os chefes do governo / não tomavam providência / e os grupos dos bandidos / viviam da violência". (SENA, 1977, p. 1).

Nota-se que as pessoas que habitam o sertão têm como hábito comum a religiosidade, já que fazem orações e promessas para obter graças, melhorias de vida, melhoria do sertão, co nsiderado pelo autor como "rústico" e "asqueroso". Acreditam também que através da lei da transformação, que Deus comanda, o sertão vai virar um lugar bom para se habitar e tornar-se-á verde e florido.

Além dessa representação cristã, nota-se a presença de outra manifestação religiosa através da figura da Negra Catimbozeira, chamada Micaela Feiticeira, ou seja, é atribuída também certa credibilidade ao paganismo, mesmo que a Igreja não aprovasse esse tipo de crença. A figura da negra aparece para fechar o corpo de Silvério para que ele pudesse lutar sem sofrer nenhum assalto quanto a sua parte física.

As características que são atribuídas às pessoas que vivem no sertão são em sua maioria aspectos com sentidos ruins e muitas vezes relacionadas à morte. Durante a narrativa são mencionadas características como: cadavéricos, pobrezinhos, magros como gravetos etc.

Por fim, percebe-se que este folheto retrata o homem, o cangaço e o 
sertão como sendo uma desgraça a ser enfrentada, um castigo a ser cumprido. A história desse homem é baseada na predestinação, como se houvesse um conhecimento teleológico a respeito de sua condição. Para poder usufruir de uma vida de prazeres, ele tem que se tornar forte através da seca, da violência e da miséria.

O folheto $O$ que se vê no sertão, de Paulo Pereira, não coloca apenas um destino para o sertão, uma vez que apresenta a dualidade entre as coisas boas e ruins que lá estão presentes. Dessa forma, ele consegue transformar esse homem do sertão em algo mais palpável, não fazendo do sertanejo uma caricatura do seu sofrimento.

Apesar de o autor passar uma visão simplificada das coisas demonstrando o cotidiano do sertão como "uma velha fiando um cordão / e um velho sentado no pilão" (PEREIRA, [19--] p.1), e também fatos corriqueiros, porém com peso sentimental negativo, como "a mulher se intriga com o marido / um caçote ingole uma tanajura" (PEREIRA, [19--] p. 2), demonstra que esse contraponto de bem e mal valida o sertão em sua forma integral, aproximando-o da realidade, que não só cheio de negatividades. Uma vez que se valesse apenas das características positivas do sertão, se voltaria para o plano utópico.

A fim de confirmar as informações mencionadas anteriormente, seguem as duas últimas estrofes do folheto, em que essas características são claramente evidenciadas:

O sertanejo tem muita animação

Quando planta em dias de janeiro

Não faltando inverno em fevereiro

Está muita aumentada a plantação

Não havendo lagarta nem verão

Em abril a colheita está segura

Não se ver uma criatura

Numa época bondosa assim sofrer

Só se houve agricultor dizer

Não há quem possa colher tanta fartura

No sertão sofre toda criatura

Quando o ano só trás dificuldade

Só se ouve falar em necessidade

Sacrifício tristeza e amargura

A lavoura não suporta a quentura

O sol ardente e o vento temoroso 
Paulo Estevão M ortati Fuzinelli; Raimunda de Brito Batista

O sertanejo muito triste e nervoso

Lamentando a triste sequidão

Que quando há uma seca no sertão

O pão da vida é mais dificultoso. (PEREIRA, [19--], p. 4).

\section{Contrapontos}

A forma de interpretar e o grau de detalhamento que o espectador tende a realizar variam conforme a situação e a experiência. Os suportes são diferentes, mas os executores têm em comum o exercício da escolha da melhor forma de adaptação, com as respectivas diferenciações, e o que há de comum para se criar identidade ou diferenciação entre romance e filme.

As características tanto no cordel quanto no filme são baseadas no histórico nordestino, no conhecimento desta população. A reprodução dessas histórias muitas vezes não se prende à verossimilhança, característica que faz estes produtos (cordel e filme) margearem a indústria cultural. $\mathrm{O}$ fator verossímil é mais notável no Cinema Novo, em que o espetáculo do cinema industrial existe fundamentado em grandes quantias de dinheiro, o que faz valer o dístico já mencionado: "Uma câmera na mão e uma ideia na cabeça".

Os dois suportes trabalham seus mitos de maneira parecida. Grandes personagens da história popular são retratadas de forma associativa. Histórias da região do Nordeste com grande valor simbólico são transformadas em referência e representadas por personagens que condensam o imaginário popular. Corisco exerce o poder ideológico e a representação de Lampião; Sebastião reúne em si todas as características de figuras como Antônio Conselheiro e Beato Lourenço, típicas daquele contexto. A falta de delimitação temporal fortalece a associação dessas figuras.

[...] O processo histórico se projeta num campo alegórico, depurando seus elementos para ficar reduzido ao essencial [...] numa transformação que evidencia um estilo de relato poético cuja inspiração está na Literatura de Cordel. (XAVIER, 1983, p. 91).

É notável que os três elementos analisados: o homem do sertão, o sertão e o cangaço, tanto nos folhetos quanto no filme, são basicamente indissociáveis. A discrepância entre as duas fontes não ocorre de maneira gritante, 
uma vez que o cangaço é representado de duas maneiras: como um símbolo do horror e também o espaço característico da vida sertaneja. No filme, porém, aparece como uma transformação radical da vontade de justiça, enquanto no cordel não há uma busca por essa justiça, apenas uma violência desordeira em que não se pode caracterizar sua real intenção.

Em relação ao sertão, no folheto A morte comanda o cangaço e no filme, percebe-se que a relação que se dá entre ambos é a mesma. O sertão é visto como um lugar no qual as pessoas residem para pagar seus pecados, como uma espécie de purgatório. $\mathrm{O}$ sofrimento é inerente àqueles que residem nesse ambiente, não existindo saída para a seca vida que os permeia. Já em relação ao segundo folheto analisado, o autor não é maniqueísta, ele equilibra a relação entre os aspectos bons e ruins do sertão, sem transformá-lo em um local onde o mal é característica crucial do ambiente.

O homem possui duas facetas: primeiramente temos aquele que é retratado no filme, ou seja, o homem que aceita sua condição, que é conformado com o que lhe é dado, passivo no trato com as autoridades, e que se transforma em uma personagem secundária na realidade local; e, em segundo lugar, o outro homem, que é o que acredita, aquele que luta e faz valer sua vontade, que vai ao encontro de melhorias fazendo de sua miséria o combustível para a mudança. Entretanto, temos o intermediário: Manoel, que após sofrer todas as dificuldades que a sua vida rural lhe proporcionou, parte em busca de uma reorganização de sua vida.

Outro paralelo que se pode traçar é o da narração. No filme, o cantador é uma das principais instâncias narrativas, incorporando a tradição do poeta pertencente àquela própria realidade. A composição de Sérgio Ricardo e Glauber Rocha é uma voz que encena na forma do folclore o cantar dos versos que servem de narrativa e comentário, sem se tornar simplificador.

Nas características cinematográficas de Deus e o Diabo na Terra do Sol não é a Literatura de Cordel a única influência, apesar de ser um grande desenvolvedor da história. No som, vê-se a influência de um processo musical erudito trazido com a execução de Heitor Villa-Lobos. No entanto, é na imagem que a pluralidade de discursos se evidencia, sendo o Cordel uma delas. No filme, o Cordel é o caminho para a identificação com discurso de raízes rurais e trabalha-se com outros processos com os quais a Literatura de Cordel deve interagir. A junção do erudito e do popular transforma o produto folclórico em inspiração, mas não o representa em estado bruto. 
Paulo Estevão M ortati Fuzinelli; Raimunda de Brito Batista

\section{Considerações finais}

Aspectos culturais podem ser indivisíveis quanto à formação pessoal dos indivíduos. Algumas vezes as pessoas podem perceber essas características e a partir delas construir opiniões, retratando o meio em que vivem, mesmo que seja de diferentes formas. Tanto o cordel quanto o filme nos mostram visões em que a cultura popular não se sobressai às opiniões.

Glauber constrói de forma alegórica - mas não caricatural - uma realidade recheada de aspectos culturais, como o messianismo e o cangaceirismo, e consegue trabalhá-los de forma que o indivíduo destaque a sua cultura. Glauber alcança o retrato da realidade de forma atemporal

$\mathrm{O}$ autor popular também compreende o acontecimento a partir de uma visão de mundo própria, em que o meio e as condições em que vive são de efetiva importância para a produção do cordel. Para Silva (2000 p. 81), a identidade é criação social e cultural. Desta forma, pode-se verificar o reflexo do meio e da cultura do povo nordestino na peculiaridade identitária do cordelista e também nas características que estão em torno a sua obra.

Portanto, a digestão dessas obras se torna difícil conforme o seu receptor. Para se entender essas obras é necessário conhecê-las e, acima de tudo, compreendê-las enquanto recorte cultural e metáfora da realidade social em geral; atribuir valores específicos quanto ao tempo e ao espaço limita a sua compreensão e subestima o seu valor estético. Entende-se, por fim, que ambas as obras - mesmo possuindo diferenciações - se completam.

\section{Referências}

BERNADET, Jean-Claude. O que é cinema. São Paulo: Editora Brasiliense, 1980.

CURRAN, Mark J. História do Brasil em cordel. São Paulo: Editora da Universidade de São Paulo, 1988.

HISTÓRIA do cordel. Disponível em: <http://www.ablc.com.br/historia/hist_cordel.htm>. Acesso em: 23 jun. 2010.

JOHNSON, Randal. Literatura e cinema - Macunaíma: do modernismo na literatura ao cinema novo. São Paulo: T. A. Queiroz, 1982.

LUYTEN, Joseph M. O que é literatura popular. São Paulo: Editora Brasiliense, 1983. 
O cangaço e o (ser)tão nacional: D eus e o Diabo na Terra do sol e a Literatura de Cordel

MERTEN, Luiz Carlos. Cinema: entre a realidade e o artifício. Porto Alegre: Artes e Ofícios, 2003.

ORICCHIO, Luiz Zanin. Cinema de novo: um balanço crítico da retomada. São Paulo: Estação Liberdade, 2003.

PELLEGRINI, Tânia, et al. Literatura, cinema e televisão. São Paulo: Editora Senac, 2003.

PROENÇA, Ivan Cavalcante. A ideologia do cordel. Rio de Janeiro: Ed Brasília, 1977.

RESENDE, Viviane de Melo. Literatura de cordel: uma aproximação etnográfica ao gênero. Brasília: UnB, 2006. Disponível em:

<http://www3.unisul.br/paginas/ensino/pos/linguagem/cd/Port/137.pdf. > Acesso em: 20 mar 2010.

SILVA, Tomaz Tadeu da; HALL, Stuart, WOODWARD, Kathryn. Identidade e diferença: a perspectiva dos estudos culturais. Trad. Tomaz Tadeu Silva. Petrópolis: Editora Vozes, 2005.

STAM, Robert. A literatura através do cinema: realismo, magia e a arte da adaptação. Belo Horizonte: Editora UFMG, 2008.

VENTURA, Tereza. A poética polytica de Glauber Rocha. Rio de Janeiro: Funarte, 2000.

XAVIER, Ismail. Sertão mar: Glauber Rocha e a estética da fome. São Paulo: Brasiliense, 1983.

Recebido para publicação em 05 jul. 2010. Aceito para publicação em: 06 ago. 2010. 